\title{
The Archives of Scientists' Transcendent Experiences (TASTE)
}

To the Editor:

Over the years many scientists, once they have realized I am a safe person to talk to, have told me about unusual and transcendent experiences they have had. Too often I am the first and only person they have ever spoken to about their experiences, for fear of ridicule from their colleagues and adverse, prejudicial effects on their career. Such fears have, unfortunately, too much of a basis in fact. It is not that there are a lot of scientists with nasty intentions deliberately trying to suppress their colleagues; it is just the social conditioning of our times.

I want to change that, and I ask your help in doing so. Scientists today often occupy a social role like that of "high priests," telling laypeople and each other what is and is not "real," and consequently what is and is not valuable and sane. Unfortunately, the dominant materialistic and reductionistic psychosocial climate of contemporary science 
(what sociologists long ago named scientism, an attitude different from the essential process of science), rejects and suppresses $a$ priori both having and sharing transcendent, transpersonal, and altered states (or "spiritual" and "psychic," to use common words, in spite of their too vague connotations) experiences.

From my perspective as a psychologist, though, this prejudicial suppression and rejection psychologically harms and distorts the transcendent (and other) potentials of both scientists and laypersons, and also inhibits the development of a genuine scientific understanding of the full spectrum of consciousness. Denial of any aspects of our nature, whatever their ultimate ontological status, is never psychologically or socially healthy.

The Archives of Scientists' Transcendent Experiences (TASTE), which I have recently opened, is intended to help change this restricted and pathological climate through the operation of a World Wide Web site in journal form that allows scientists from all fields-from anthropology through botany through mathematics through physics through psychology through zoology, to name just a few-to share their personal transcendent experiences in a safe, anonymous (if they wish), but quality-controlled space to which many people have ready access.

Specifically TASTE, to various degrees, (a) allows individual psychological growth in the contributing scientists by providing a safe means of expression of vital experiences; (b) leads toward a more receptive climate to the full range of our humanity in the scientific professions, which, in turn, will benefit our world culture at large; (c) provides research data on transcendent experiences in a highly articulate and conscientious population (scientists); (d) facilitates the development of a full spectrum science of consciousness by providing both data and psychological support for the study of transcendent experiences; and (e) helps bridge the unfortunate gaps between science and the rest of culture by illustrating the humanity of scientists.

Please take a look at the TASTE site: the URL is $<$ http://psychology. ucdavis.edu/tart/taste> or, if the Psychology server is off line, you can use <http://www.issc-taste.org $>$. If you find it valuable, please pass this information on to friends and colleagues. I have no budget for advertising, so must depend on word of mouth to get this information around.

If you have a web site of your own that would be suitable for a link to TASTE and can add one, thank you! Feel free to copy one of the TASTE experiences as an example on your web site, if you like. (I also have an attractive copy of this announcement in html format, including the TASTE logo, that I would be glad to send you.) In terms of more 
conventional, slower publicity, if you can recommend any journals I should send notices to, please let me know. If you are the editor of any publication, you have my permission (and thanks!) to print this notice in your publication. Thank you!

Charles T. Tart, Ph.D., Editor Professor Emeritus of Psychology University of California at Davis Professor, Core Faculty Institute of Transpersonal Psychology 744 San Antonio Road Palo Alto, California 94303

Fax: (630) 604-3279 e-mail: cttart@ucdavis.edu

Home page \& archives: http://www.paradigm-sys.com/cttart/ The Archives of Scientists' Transcendent Experiences: http://psychology.ucdavis.edu/tart/taste/ 